\title{
The multiple interfaces of engagement: towards a new conception of gallery learning
}

Christopher Whitehead*, Emma Coffield**

\begin{abstract}
Drawing upon longitudinal research undertaken with Further Education students who visited an art exhibition, this article retheorizes organized gallery learning. We argue that the significance of the gallery visit for students - and of their engagements with the exhibition and artworks - is elaborated and remediated over longer periods of time and through multiple 'interfaces'. These include: the school or college; the gallery and the contingency of gallery events; the exhibition; internet websites, social media and mobile applications; the artwork and images of it; and an understanding of the self and other people (including the artist, teachers and gallery staff). Each of these has different possibilities that structure engagement, and sometimes interfaces 'fail' because of mundane contingencies or students' dispositions. Also, interfaces don't stand alone and need to be considered relationally for a more holistic and complex picture of 'learning' to emerge, in which the sites, situations, politics, logics, subjectivities, and techniques of knowledge intersect over time.
\end{abstract}

Key words: Gallery learning, interface, engagement, young people, Artist Rooms

\section{Introduction}

Consider this scenario, which happens to be a true story. At considerable expense, after much painstaking collaboration and negotiation between a college and a large museum, and some in-class pre-visit work, a group of 16-18-year-old students are loaded onto a coach to visit an exhibition at the museum. The museum is the Bowes Museum in the north of England, and the exhibition is of photographs by Robert Mapplethorpe. The instrumental purpose of the visit is, for the Museum, to engage young audiences and schools with the exhibition, and, for the college, to link the exhibition to coursework, and inspire students to learn from what they see and do well in their assignments, and ultimately, in the long-term, to help them have richer lives, whether personally, professionally, or both.

For those who work in or with museums, this is a familiar scenario, and we often concern ourselves with ensuring or measuring its outcomes, in terms of what the young people learn through the central episode of the visit, and what this does for them, insofar as this can be easily and economically understood in the short term. But this leaves unopened some other questions. Do students always learn as they are supposed to? What do they, and other actors (human and non-human), bring to the visit that changes its course unexpectedly? What happens around the visit? In what ways, other than those prescribed, do students engage and 'learn'? About what, and through what means and technologies? In what spaces or times of their complex daily lives does this happen? How might all of this interrelate and cohere (or not) into something meaningful?

Public art museums have from their inception played an educative role, yet over recent decades this has intensified because of political-instrumental agendas and the repositioning of museum missions towards public use. A significant field of study has grown around this. Special attention has been paid to the needs of a diverse range of audience groups (e.g. 
children, young people, older people, families, tourists, those with disabilities etc.), societal purpose (i.e. where the museum or gallery is positioned as an agent of social change, as discussed in Sandell 1998, Newman and McLean 2004, Brown et al 2016), and the potential tools for measurement and/or 'outcomes' that engagement in a learning programme might deliver (e.g. Hooper-Greenhill 2004).

Much of this work, and particularly that published after the late 1990s, shares an understanding of learning as active, situated, involving the personal and the social, and portrays learners not as 'empty vessels' but as participants, collaborators and experts (e.g. Falk and Dierking 1992, Hein 1998, Hooper-Greenhill 1999, Simon 2010, Kidd and Cardiff 2017). However, as Pringle and DeWitt (2014) recently noted, 'an understanding of how and why learning occurs in the context of the art museum remains incomplete'. For example, there is little work that distinguishes between engagement with an artwork, images of that work, the exhibition, and the college or school, or how these forms of engagement each afford specific structural conditions that delimit and potentialize agency and position the actors and knowledges involved. The turn towards understandings of the active learner has been welcome, but we make a case for corresponding focus on what we call the 'interfaces' of learning, which also need to be seen as active, each in particular ways.

Moreover, while there is widespread recognition in both practice and research that learning takes place before and after any visit, relatively little research has considered the multiple sites of learning as connected to or associated with the gallery visit over time. Falk and Dierking's The Museum Experience (1992, 2013), the contents of which are explicitly organised into 'pre-', 'during' and 'post' visit sections, is an exception to this (see also Griffin 2004 and Marty 2007). Yet even here the museum visit is the predominant factor around which 'other' contexts, experiences and motivations are arranged. The museum or gallery therefore continues to be identified as the primary site for learning, everything else being subsidiary. Likewise, the evaluation of gallery programmes and events are often restricted to the episode of the visit, albeit for practical reasons. One important consequence of this is the bracketing-off of the gallery and its contents as a 'special' environment, held at some remove from potentially overlapping environments such as school, college and home, as well as what we might call the 'psychic' spaces that people inhabit in the form of activities, hobbies, knowledges, attachments and relationships, and in which they make sense of things.

This paper contributes to an expanded scholarship of 'gallery learning', one that critically considers how a group of Further Education photography students engaged with art beyond the time and place of the visit, and as situated within the far broader context of a life lived. As our opening scenario suggests, museums and galleries are often called upon to play a 'transformational' role in the lives of young people, and academics and practitioners alike invest huge amounts of energy and care discussing, for example, how they might meet the needs of 'twenty-first century citizens' in order to 'make a difference' in their lives (Xanthoudaki 2015: 247; see also Soren 2009). In order to meet such a challenge, art museums and galleries need first to better understand the nature and specifics of young peoples' involvement and consider how engagement may be elaborated over longer periods of time and multiple locations, as well as over epistemologies and value frameworks that may be canonical and structuring (e.g. art history, assessment criteria, etc.), or personal (e.g. relating to self-perception, values and identity).

We focus here on young peoples' engagement with contemporary art as remediated and elaborated upon, within and beyond the episode of the gallery visit. To do this, we identify and discuss a number of 'interfaces'. Our concept of interfaces moves beyond common understandings of a 'point of contact' and draws upon and significantly develops approaches common in Human-Computer Interaction $(\mathrm{HCl})$, to include not only certain 'screens' but other environments, whether physical or cognitive in nature - college; the gallery; the exhibition; internet websites, social media and mobile applications; the artwork and images of it; and an understanding of the self and other people (including the artist, teachers and gallery staff). Each of these has specific conventions, conditions and affordances, and it is through their seriation and interaction that learning takes place. 


\section{Understanding interfaces}

In museum studies, the term 'interface' is most often used as a metaphor for a point of contact between groups of people, the museum, the collection, an object, or understanding. For example, the term 'interface' has been used more or less casually to describe: the relationship between the artist and the museum (Barrett and Millner 2014: 6); between directors and trustees (Suchy 2004: 125); internships in museums as organised by Higher Education providers (Beckmann 2013); the moment a beam of light hits an object (i.e. the 'air-object interface' as described in Johnston-Feller 2001: 79); or more broadly, the point where the visitor and the museum, its contents, collections and resources meet. Falk and Dierking call for 'every facet of the museum's interface with the public to be analysed' (2013: 255).

Within $\mathrm{HCl}$ approaches however, the term 'interface' tends to more specifically denote a surface, screen or digital system for accessing 'data' or 'content', where that content is perceived to be somehow beyond or behind the screen (Drucker 2001: 9) and the 'user' in front, so that a physical and apparently neutral screen or system stands between two parties. The function of the interface here is one that might be rendered more or less efficient through the process of design. For example, in Yu-Chang Li and Wee-Chung Liew's (2015: 208) work on digital curation, the term 'interface' denotes the 'front-end' component of a mobile digital prototype through which visitors can interact with a 'back-end' object database in order to arrive at a personalized museum tour.

Similarly, Mayrand (2001: 406-7) has argued for 'exhibition design' as an interface by situating design between visitors and the museum's 'content'. Indeed, Mayrand goes on to borrow 'from the computer world' to suggest that clear conventions, user-friendly design, transparency (where the interface 'disappears' in favour of the 'content' of the experience) and engagement might all influence the efficiency of this interface. He notes that if the 'conventions of the interface become too complicated, too subtle, or are constantly changing [...] few of us can adhere to them, and the interface breaks down' (Mayrand 2001: 407).

We agree with Mayrand that interfaces, seen in this sense, are 'noisy' and contain the possibility of interruptions and interference within their transmissions. Further to this, we argue that interfaces are epistemological, whether by design or by accident. They don't allow for any and all kinds of interaction, and the structuring nature of the interface isn't neutral. Interfaces can enable or disable, frustrate, remove from view, make actions possible or impossible, thinkable or difficult to bring to thought, perhaps because such actions and their epistemological grounds were unconceived or unthought at the moment of design, or were impossible to render. The 'data' too is in a fundamental sense inseparable from the interface that structures and presents it for specific kinds of apprehension. To compound this, Marshall McLuhan (in 1971) suggested that the 'user' is in fact the 'content' that is metamorphosed by the interface (Molinaro et al 1987: 397). Both of these views break down the view of the interface as transparent screen between information and (human) user into something more interactional and generative.

\section{Taking interfaces from $\mathrm{HCl}$ to humanities}

As Drucker (2011: 1) notes, interfaces are talked about in $\mathrm{HCl}$ in a deliberately mechanistic way concerning efficiency for purpose, but it is possible to both rethink the interface as a humanities paradigm and to widen the scope of what might be considered an 'interface'. Drucker suggests, for instance, that we substitute for the 'user' imagined in $\mathrm{HCl}$ studies a 'subject' familiar from literary and cultural studies, opening up an equally familiar framework of dynamic constitutions or 'space of relations' between a (never-)finished text and its reader. In this sense, interface theory becomes nothing less than 'an extension of the theory of the subject (Drucker 2011: 8). Drucker further includes, as possible interfaces, 'a book [...] a newspaper page, a bathroom faucet, a car dashboard, an ATM machine' (Drucker 2011: 10) as well as invoking the window, the screen, the desktop, the mediating environment, the 'surface where the necessary contact between interactors and tasks [allows] functions to be performed (following Laurel 1990), a 'dynamic space of relations' (Drucker 2011: 3) and a 'zone of affordances' (Drucker 2011: 7). 
The idea of the interface is metaphorical, and each of the above contain suggestions and limitations. The 'window', for example, suggests a transparent screen that allows us to engage with what is 'out there' (and constructs here/there, in/out binaries), but of course the shape, position, opacity, passability, framing and accoutrements of a window may all determine our 'view' in ways that speak to the power and politics of mediation, and also to chance. Indeed, Drucker's paper is animated by a degree of frustration at the difficulty of arriving at any one final metaphor or clear definition, beyond noting that the interface has to be 'theorized as an environment in which varied behaviours of embodied and situated persons will be enabled differently according to its many affordances' - a statement she herself describes as 'so maddeningly vague and abstract' as to seem 'almost useless' (Drucker 2011: 12).

A plethora of objects (and more) might then count as interfaces, although as we write it is still the flat, page-based or screen-based environment that dominates thinking, perhaps because of its continued dominance within the lifeworlds of subjects. In what follows, we take up and extend Drucker's approach, arguing for interfaces of varying kinds, and mixtures, intersections and layerings of them. They can be spatial like a museum gallery, digital like a website, material like the mount, frame and glazing of a photograph on the wall, and psychic or cognitive, like schemas that a museum visitor calls upon, affording particular modes of sense-making to open spaces of imaginative dialogue, encounter and apprehension - in our case students' senses of self and their constructs of Mapplethorpe. In abstract and concrete senses, interfaces can be simultaneously 'screens', 'devices' and 'spaces' that (should) enable reception and transformation.

Are human actors necessary within an interface paradigm? Ash (2015: 1) argues that interfaces can be meeting points for non-human agents, or technical objects such as software codes, and he problematizes approaches that position the interface as a bridge between two distinct modes of being, and in so doing 'reiterate an instrumental logic that reduces the interface to tools used to complete human tasks' (Ash 2015: 16-17). Ash's appeal to think more carefully about the divisions and relations produced through the interface is a helpful challenge, restoring agency to the non-human while retaining a sense of the effects of design intentions. In this sense, our research might have proceeded by examining the encounters between objects in and behind an exhibition, from lorries and crates to frames, mounts, lighting systems, light, walls, dust and so on. That will be for further research, however, and here we focus on young peoples' engagements, and thus on interfaces for human use.

At the grandest scale, certain discursive notions of 'culture' might be viewed as a kind of interface. For example, the 2016 Culture White Paperproduced by the government's Department for Culture, Media and Sport (or DCMS) in the UK states that 'we want everyone regardless of background to have the opportunity to experience culture. This is because culture opens doors, improves social mobility and has an impact upon life chances'. ${ }^{1}$ The term 'interface' isn't used here (usually it isn't), but these few lines nevertheless mobilize conventional associations of the interface as equipped with certain intentions, effects and 'proper' modes of use. This can, of course, contrast with practice as it happens, the ways in which people behave and act with particular interfaces, and with others that they may use as alternatives, as we discuss below.

\section{Idealised interfaces - transformation and failure}

The interfaces described above each carry with them an idealized sense of transformation - even by us, the authors, as we type these words, 'transforming' ideas into arguments, moving passages of text around and organizing them for better effect before submitting our work to a second interface, the journal, whose wider ideal effects might be that we transform, in some degree, your understandings. Interfaces, in this sense, are set up as transformation machines, and it is compelling to think of gallery learning as an interface into which are built certain ideal notions - generated in the discursive space between social and cultural policy - of transformation as affordance. In its most blunt form, this may equal the notional 'life-changing' encounter with culture (whether that be Mapplethorpe or Mozart) that sets a person on course for success, be it the development of an abiding interest that is more socially acceptable than crime, inspiration for a career, or just 'enrichment' in the sense of socially-sanctioned consumption of elite culture. 
But this is where cautions come: just as the idealized transformations that a digital interface affords can be interrupted, derailed or simply not perceived or grasped by subjects, so too the ideal transformations with culture in the museum or gallery can fail. Here we might turn to that body of museological literature that concerns how and why engagement by visitors is discrepant with the intentions of museum producers, on account of renegade decoding or social anxieties about engagement with elite culture in elite cultural spaces that disable museal pedagogies from having the desired effect (beginning with Bourdieu and Darbel 1969). Or to the ways in which engagement is structured by the specific 'affordances' in question, in James Jerome Gibson's sense of specific 'action possibilities' (1977). These are 'qualities of systems that... present interactions for an individual to participate in' (Greeno et al 2000: 278) that can be affected by constraints like conventions, protocols and contingencies (such as acceptable behaviour in the gallery, ways of looking, the bureaucratic and logistical practices of college trips, mishaps and sudden dips in funding or interest) which can be disaffecting and uncomfortable for some subjects, notwithstanding producers' intentions.

Bearing this in mind, we advance the concept of 'interfaces' as physical and nonphysical environments that make possible multidirectional, multidimensional and multi-temporal engagements with and through artworks. Interfaces in this sense aren't simple points of contact, nor is our examination restricted in application to certain screens or devices. This isn't to say that the literal screen interface is uninteresting, and indeed a great deal of our participants' engagement took place online, for crucial reasons. Rather, the screen isn't the only 'zone' or 'environment' that we can usefully think of using the idea of the interface. Moreover, the idea of the screen (or window for that matter) doesn't easily accommodate the experience of moving through a gallery space, while the idea of a mediating environment, which might, is difficult to square with other 'spaces' that can be thought of as interfaces - even spaces of psychological play, as we later discuss.

These ideas might be brought close to other critical frameworks that attempt to account for the structural determination of consumption - e.g. as found in theories such as the gaze as a learned practice of disciplined looking, frame theory, encoding-decoding, reader-response and reception theories - but an inclusive understanding of the interface takes our analysis somewhere different. It allows for the possibility that engagement with and through artworks happens across multiple spatial, physical, digital and cognitive 'sites', each with their technical controls, diachronically and sometimes synchronically too. As an example, each of these is not just a 'frame' of assumptions about what matters (Kidd 2011; Whitehead 2012) but is also an arrangement of 'action possibilities' that offer subjects specific techniques of engagement. This helps us to capture the complex longitudinal nature of engagements only partially situated in the physical space of the gallery.

\section{Rethinking young people's engagement with art}

The research project took as its focus 'The Magic in the Muse' exhibition on display at the Bowes Museum, County Durham from 27 November 2015 to 25 April 2016. Part of the ARTIST ROOMS (AR) touring programme,,$^{2}$ the exhibition was dedicated to American photographer Robert Mapplethorpe, and consisted of 25 of his works, each individually labelled and arranged via three themes (celebrity, classical poses and movement ${ }^{3}$ ). A key condition for the loaning of works from the AR collection is that staff at the receiving venues work to engage 'new' young audiences, and so a number of events, including workshops, educational visits and tailored projects were offered to local education providers, including the 'Impossible Project', whereby young people were invited to send in a single black and white polaroid-style photo for display. For the duration of the exhibition, young people could also register with the Museum in order to see the exhibition for free, avoiding a fee of $£ 6$ for students or $£ 10.50$ for adults. ${ }^{4}$

Between October 2015 and March 2016, we worked with a single group of FE photography students from a local college, as well as with their tutors and Museum staff. A qualitative mixed-methods approach was adopted to investigate engagement longitudinally and in depth, over multiple locations. This included: (i) observation of an hour-long briefing given to students by a member of the Museum staff on the college campus several weeks before the trip; (ii) observation and visitor tracking of the subsequent daytrip to the Bowes 


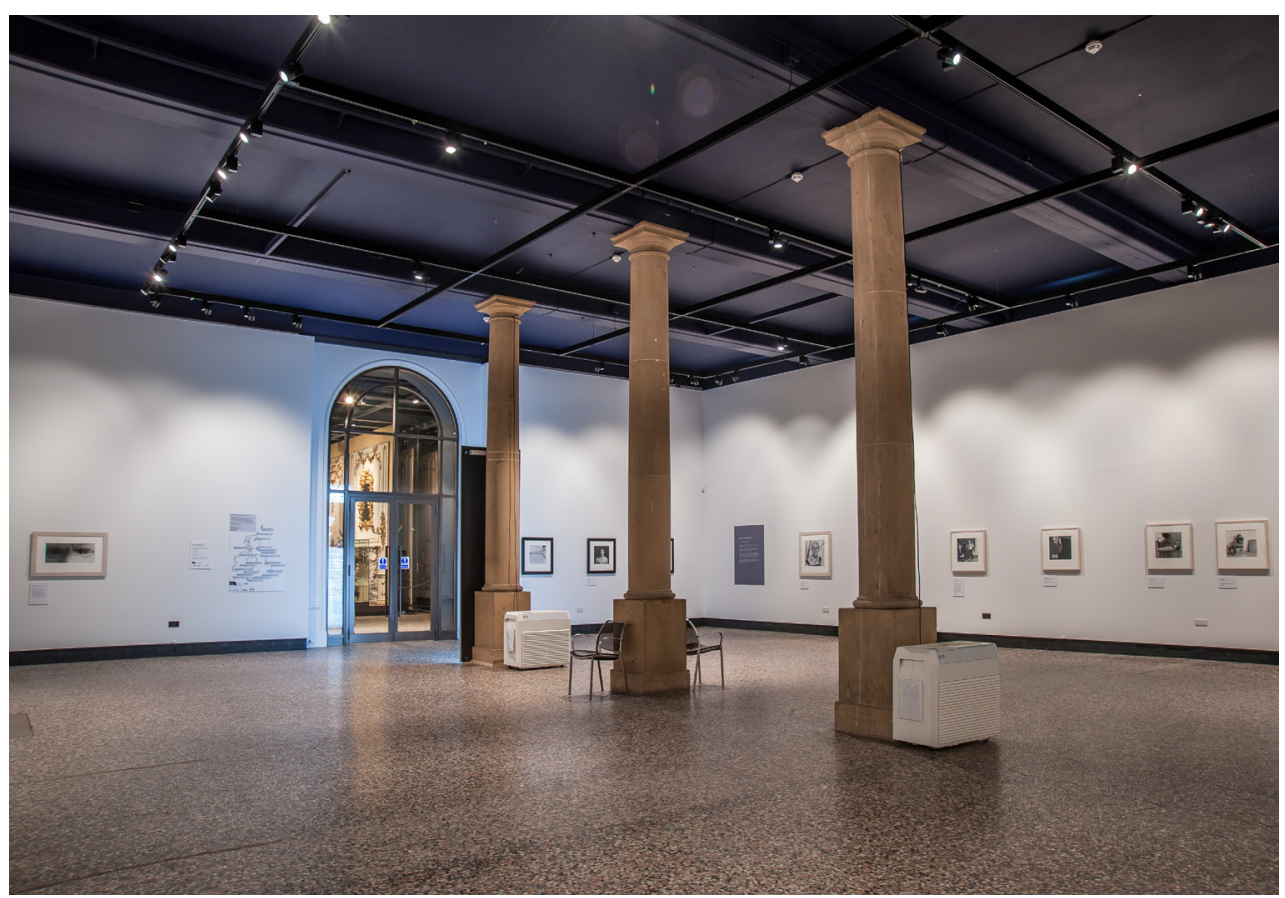

Figure 1. Interior image of 'The Magic in the Muse' exhibition. Reproduced with permission from The Bowes Museum, Barnard Castle, County Durham, England

Museum involving 32 students and three college tutors who undertook an hour-long staff-led tour of the exhibition, followed by independent exploration; (iii) four workshops with a total of ten students, held on the college campus six weeks after the trip to the Bowes Museum; (iv) pre- and post- trip interviews with two college tutors; (v) pre- and post-trip interviews with two members of staff at the Bowes Museum (one of whom was involved with the exhibition, the other the gallery learning programme).

Students who chose to be involved in our workshops were asked to draw a timeline, starting with the point they first heard of Robert Mapplethorpe and/or the exhibition, and then to mark everything they remembered or associated with the exhibition until the present day. Further questions and prompts encouraged students to elaborate on how and why this engagement had taken place (or not), and students were given every opportunity to express their views freely. The workshops and interviews were recorded and selectively transcribed. Interview and workshop data were coded inductively to map out constellations of linked practices, understandings, ideas and values, as well as the 'evidence' provided by participants and areas of emphasis or exclusion. We began 'outside the box' insofar as this is possible, which is to say without a necessary-and-sufficient definition of learning, or fixed categories of learning to look for in the data. This was in order to provide a sufficiently open analysis capable of informing new theorizations. However, we were receptive to the possibilities that learning might be (or seem) scant, and that the objects and techniques of learning might not always be those idealized in policy or anticipated by organizers at the college and Museum. Learning was seen as a developmental process, certainly not limited to the accumulation of knowledge 'about the art'. Accounts were then compared and analyzed so as to identify patterns, similarities, boundaries and differences across the data. Below, students are referred to by a self-selected pseudonym. ${ }^{5}$ 


\section{Identifying interfaces}

In the remainder of this article we critically consider a variety of interfaces, each of which punctuated, extended and/or remediated students' engagement. We include in this the college; the Museum; the internet; the artwork/images of the artwork; the exhibition; the artist; the self. We don't see this list as exhaustive, and might easily have further included social media, the Museum shop, ARTIST ROOMS, books and magazines, students' cameras, and so on. We concentrate below on a select number of interfaces and findings that we consider the most important contribution towards an expanded understanding of gallery learning.

\section{The college-as-interface}

Rather than the museum, the college was the primary, and indeed organising, interface through which students engaged with and explored the exhibition and the artworks it contained. The nature of the trip and all the work that surrounded it was heavily structured by the requirements of the college, e.g. by the term-long project designed, introduced and assessed by college tutors of which the trip was a part; the resources made available during this period; the timing of the visit within the school year and in relation to the arrival and departure of the college buses; the activities and outcomes required to meet assessment standards; and the codes of conduct and guidelines for trips as set out by the college.

The students' timelines, produced during the workshops, make the importance of the college-as-interface clear. Nine out of ten students began with the moment they were told about the forthcoming trip or were 'introduced' to Mapplethorpe's work. In either case, this 'introduction' was facilitated by tutors, on campus and explicitly linked to the current course of study. Students then commonly proceeded to mark out activities chronologically (as the workshop directed) including an instruction from tutors to carry out research into the Museum, exhibition and artist before the trip, and a later prompt to consider how this new experience of Mapplethorpe's work and increased knowledge of his practice might influence their own. Students also frequently noted that they were required to present evidence of the trip as part of their assessed work. From a multitude of possibilities, the college enabled and encouraged only certain select kinds of encounter, and it further arranged and equipped these with particular modes of use (e.g. students were directed to specific information), ideal functions and long-term intentions (that the information gathered might 'transform' students' work and understanding, and that this could be both evidenced and rewarded).

As an example of the way in which the college structured engagement, one student, Henry, noted that because a tutor had introduced him to Mapplethorpe he knew the artist was 'someone to look into'. ${ }^{6}$ Henry later added that during the trip he had been 'thinking about how it relates [to my project]', that the layout of the exhibition had suggested to him a method by which to demonstrate 'progression' in his work (something he had been asked to improve upon) and that he had taken photographs specifically for his assessed work in order to 'get good grades at the end'. ${ }^{7}$ Several students made similar remarks, suggestive of not just a prompt to perform a set action but of the conferral of value and status, and the rendering of a particular way of seeing as desirable. In other words, students weren't only told to look and think about art, but how to do this, and to such a powerful degree that the 'data' of the exhibition became inseparable from the interface of the college. For Henry, the exhibition and artworks didn't have autonomous value in themselves; in his thinking they were fundamentally attached to the organized pedagogy and offered a resource from which he might extract ideas and materials, as directed by tutors and the demands of his assignment, and in relation to which he might perform a certain kind of studentship.

This is particularly interesting because the students were, at least for the duration of the trip, off site, and a key aim of the tutors had been to 'get out' of the college and 'open students' eyes' to 'different experiences'. ${ }^{8}$ Yet familiar mechanisms, procedures and expectations established within the college were imported into the Museum. Tutors went to great lengths to complete electronic registers, actively controlled the movement of the group, and encouraged or prohibited certain behaviours (e.g. asking students to listen quietly at times, calling upon 


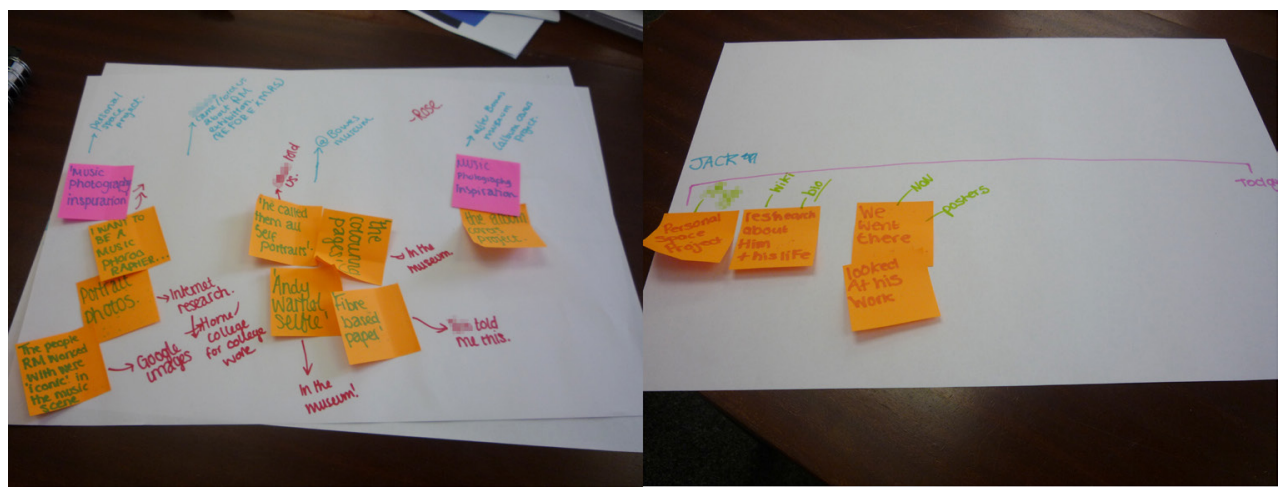

Figure 2. Image of workshop material produced by Rose (left-hand side) and Jack (right-hand side). Additional names have been removed.

them by name to elicit questions at others). The college-as-interface not only dominated students' engagement with the exhibition, but also sought to influence, regulate and bring into alignment 'other' interfaces.

This isn't to say that the college-as-interface always succeeded in bringing into being the functions and transformations desired. Additional attempts at taking a register during the visit were abandoned due to poor mobile phone reception. More significantly, although the college-as-interface encouraged an extended period of engagement, individual 'take up', as suggested via the timeline activity, varied considerably. Some students filled their timelines with thoughts and activities [see Figure 2], but Jake noted only the point at which he heard about the exhibition and three largely descriptive statements pertaining to his behaviour and expectations during the trip. The 'post-trip' section was blank. Jack and Jane similarly indicated that they could recall nothing relating to the exhibition, artist or Museum after the trip ended, while Louise explicitly remarked 'it [the trip] didn't influence me in any way'. ${ }^{9}$ Of course, the timelines produced by Jake, Jack and Jane, and Louise's comment, are not 'proof' that the trip had no further impact - just as Henry's timeline is not 'proof', on the other hand, of his studentship. It could be objected, cynically, that Jake's blank timescale or Louise's comment were performances of identity and nonchalance, or disinclination to play along. We can only say that our impression as interviewers was that this was not so. Such responses appeared to us not as false recollections, but rather as authored accounts given at one particular moment, of their longitudinal non-engagement. And of course, a single workshop activity cannot straightforwardly capture and record complex engagements as they unfurl. What we would instead cautiously suggest is that even the ideal transformation(s) encouraged by this most dominant of interfaces might yet fail or be frustrated and refused.

\section{The museum-as-interface}

The college-as-interface dominated student accounts, but interfaces do not operate in isolation. Rather, they bump against, complicate, extend and collide with each other (Laurel 1990). Thus, we might further identify an overlap between the college-as-interface and the museum-as-interface, both of which are structured by similar assumptions (that artworks are worthy of sustained attention) and ideal transformations (that students should benefit from certain acts of looking and thinking, that the trip should be memorable etc.). Perhaps on this account the two interfaces at times interlocked to mutual benefit. The free entrance offered to young people who registered allowed the college to afford the trip, while simultaneously boosting the attendance of a key audience group for the Museum and fulfilling the particular engagement requirements of the AR programme that venues must meet in order to receive one of its exhibitions.

At other points this overlap wasn't as straightforward. Students tended to use college tutors, rather than Museum staff, as a means by which to mediate the Museum and made very 
little mention of exhibits deemed key to the wider collection (e.g. the iconic and much-loved Silver Swan automaton, a star exhibit at the Museum). In fact, when asked about the free time they had been allocated, students often simply confirmed that they had 'looked round'10 or had taken pictures of 'everything else', ${ }^{11}$ without providing further detail. This is suggestive of a potential 'gap' or breakdown between the interfaces; students had been purposely 'released' from the college-as-interface to do as they wished without instruction or guidance, and they appeared to be familiar with the conventions associated with 'looking' in the Museum, but seemingly still didn't or couldn't wholly engage with the Museum's offer of meaningful engagement with 'other' artworks, objects, collections and resources.

This wasn't the case for everyone, or everything. Jake stated that he 'enjoyed and was attracted to classical art more than I kind of was at that [the Mapplethorpe] exhibition', later adding that he had 'guessed it'd have classical art there because obviously it's a classical building'. ${ }^{12}$ Similarly, Patti perceived the Museum's role to be to show 'what it used to look like [in the past]', ${ }^{13}$ while Jack referred to the Museum as a 'manor house' ${ }^{14}$ (in fact the Bowes Museum is a purpose-built art museum in the style of a French chateau). This tendency to interpret and position the Museum as 'older' than the work in the Mapplethorpe exhibition often led students to reframe or modify the aims of the trip - and thus unwittingly to employ the museum-as-interface as a means by which to extend the intentions set out by the college-asinterface - so that alongside the set intention to learn about the work of Robert Mapplethorpe students talked of learning about 'history and geography', ${ }^{15}$ or the importance of 'knowing about the past'. ${ }^{16}$

Some students brought more personal memories to bear. Jane talked of her prior attendance at a photography workshop held at the Museum, adding that this had been 'where I developed my love of photography, from the Bowes'. ${ }^{17}$ In response, Henry stated:

Henry: I've been quite a few times, you know with my family and stuff, and I went when I was a little kid and there was this one painting that I loved as a kid and I still love it now.

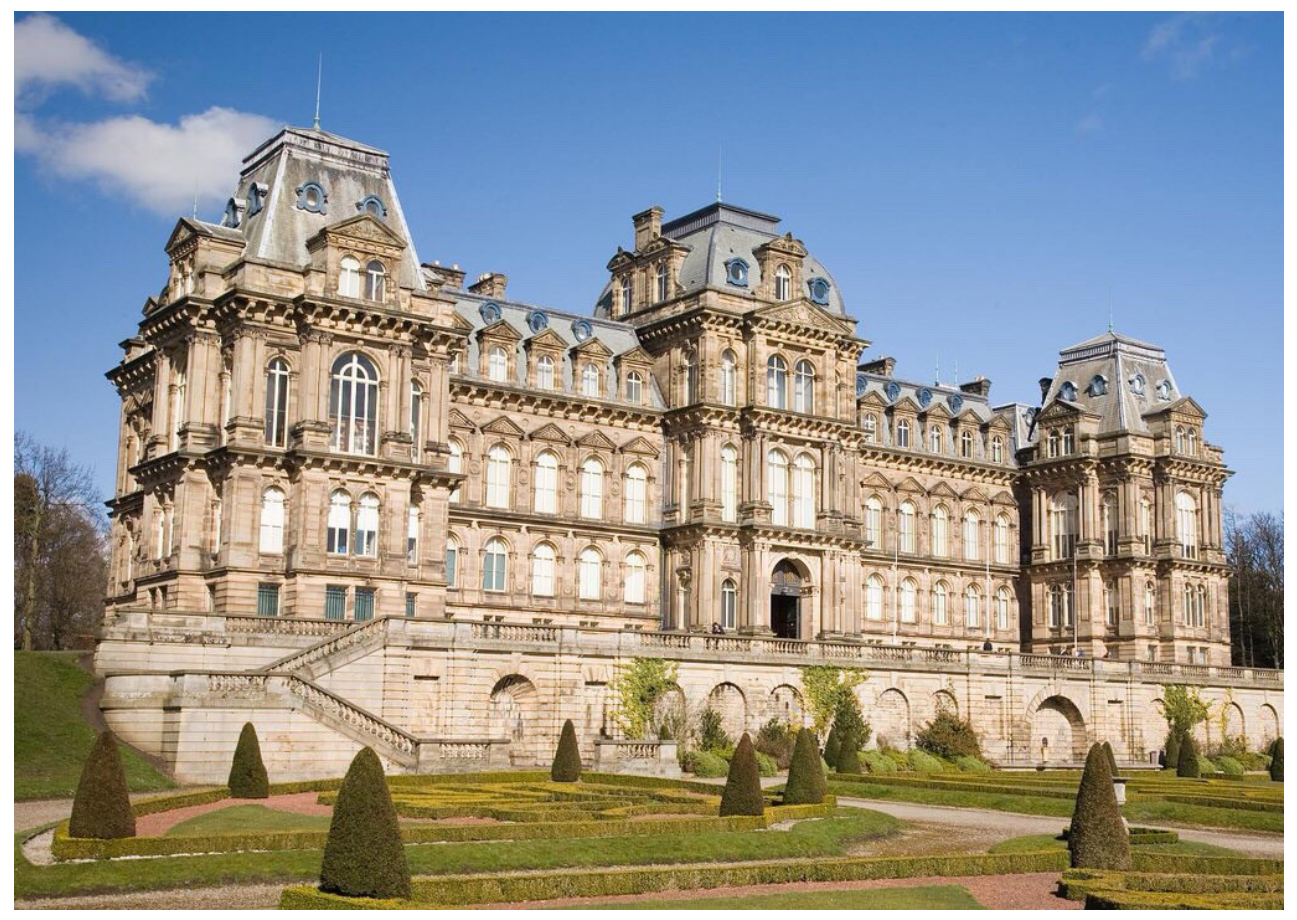

Figure 3. Exterior image of 'The Magic in the Muse' exhibition. Reproduced with permission from The Bowes Museum, Barnard Castle, County Durham, England 
Researcher: Which painting is that?

Henry: It's as you first go in, and it's, like, it's of the river and there's all the boats on it [...] and I was sat on the bench for ages, it just reminded me of being a kid. ${ }^{18}$

Jane added:

Yeah the same, it meant more for me actually going to the Museum than going to the exhibition because of past experiences. ${ }^{19}$

Both Henry and Jane articulate a certain kind of encounter, and one enabled in part by the museum-as-interface (e.g. the opportunity to view a particular painting in a particular manner) and in part on personal experience. Clearly the latter wasn't open and available to all - only Henry was able to 'use' the painting as a means by which to reflect upon his childhood, and only Jane could trace a history of her interest in photography that began in the Museum. It is in instances such as these that we see how interfaces, and the regulated encounters they appear to offer, might yet result in diversified and personal outcomes. An 'object' of learning i.e. some thing that Henry and Jane have learned about - is hard to quantify or identify, but the experience of relaying between the past and present of one's life perhaps involves an ineffable development of the self through meditative recapitulation. This speaks to both the difficulties and richness of thinking about 'gallery learning', which can easily transgress, sidestep or transcend authorized disciplinary ways of knowing such as those associated with the academic practice of art history or fine art. Since these students' reflections also involve life histories, they also confirm a basic tenet of constructivism as theorized in museum studies: no-one comes to the gallery as a 'blank slate' (Mason 2005: 223). But we note also that 'learners" constructions of knowledge take unauthorized, unpredictable and personal turns.

\section{The internet-as-interface}

Athird interface, the internet, is particularly interesting because its structure and the activities and knowledges it enabled differed significantly across a variety of locations. The students indicated that the internet was the primary means of conducting research (very few mentioned magazines, and only one a book). This activity was largely facilitated on campus and in alignment with the modes, functions and outcomes afforded by the college-as-interface - students searched for specific 'data' at the request of tutors that might be inserted directly into their assessed work. As Rose noted, 'the more pictures you have, the more educated your decision looks'. ${ }^{20}$

Contrary to the spirit of Rose's idea, not all information accessible online was made available to the students, at least while on campus, because the college firewall actively prevented them from looking at Mapplethorpe's more sexually explicit imagery. The Museum too had decided against presenting this material. Yet both Museum staff and college tutors recognized that the project and trip would likely result in the students encountering this work. As a result, they both purposely 'flagged up' the missing images, telling students, for instance, 'as soon as you Google him you're going to see a lot of unforgettable images, and that's fine, so long as you understand the context'. ${ }^{21}$ Students were thus well-aware of the existence of the images, and many bypassed the college firewall simply by going home, or elsewhere, and searching online for them there. Yet the values and permissions set up by the college-asinterface meant that those same students tended to ignore this knowledge, rather than drawing it into their work as they might have otherwise been expected to do. Jack remarked that she had selected only the images 'we were allowed to look at' for her assessed work, adding, 'there's some proper rude ones, I don't think we're allowed to put [...] that much in our book'. ${ }^{22}$

Students commonly recognized the structural make-up of each interface, noting that neither offered a 'complete' repository of images. Daisy commented that 'you can see more stuff online' but noted that the Museum contained 'things you might not have seen [online]'. ${ }^{23}$ For Patti, the internet-as-interface collided with the museum-as-interface more significantly. Noting that she 'couldn't afford to go anywhere', ${ }^{24}$ Patti illustrated how she used the internet to collapse distance, time and opportunity, and to afford encounters with artworks and exhibitions 
not otherwise available to her. But these encounters also raised Patti's expectations: having seen 'things hanging from the walls' and exhibitions painted 'half black and half white' online, she thought 'The Magic in the Muse' exhibition would be 'a bit more out there' and was disappointed to find 'it was just like a [pause] museum, don't touch anything, that's what it felt like'. ${ }^{25}$ The internet-as-interface here both punctures and determines the experience and perceived value of another.

Some students noted the relative ease of use of the internet, as opposed to the Museum visit. Nicola commented, 'I think out of like 100 photos that could be there [at the Museum] l'd probably like one of them so [...] then it's kind of a waste of time and money to go there'. ${ }^{26}$ Interestingly, Nicola suggests that there is little difference between a 'first-hand' encounter with an artwork and an image of that work online, other than the costs involved in the former. We explore this idea further below.

\section{Artwork/image-as-interface}

Throughout the project, we were keen to understand if and how artworks and images of them afforded different kinds of engagement - or even if students distinguished between the two. Nicola and Jessica saw no such difference. Nicola, when asked to compare artworks and online images of them, replied 'it's the same thing [...] it's just photos of work on the wall'. ${ }^{27}$ Nevertheless, students were repeatedly directed to perceive the increased value and significance of the exhibited artwork, which was positioned by both the college and Museum as an object of comparative significance. Indeed, the fact and effort of the trip, as well as the preparatory research and the sustained acts of contemplation required of students when at the Museum all served to reinforce this logic. Again then, we see students frustrating the encounter and transformation intended, although it wasn't clear in this case if this was a purposive resistance, a failure to perceive the terms set, or a breakdown in logic caused by the visual similarities across the two interfaces (i.e. sculptural artworks may have afforded a different response).

Aside from the exceptions noted above, the majority of students did describe a valued encounter with artworks, although they often struggled to account for this when questioned. Rose, for instance, noted that the artworks in the exhibition were 'more real' and 'more textured', and that while 'Google images spread', the artworks in the exhibition would have been presented in 'a way that he [Mapplethorpe] probably would have wanted it to be presented'. ${ }^{28} \mathrm{~A}$ detailed act of looking is implied, informed by the properties of the artworks and the intentions of the artist. For Jane, the artwork prompted a sense of personal connection that the image didn't: 'you feel like you can see just that little bit of what they felt, and what they see [sic] when they took the photo'. ${ }^{29}$ Yet while Henry initially suggested a 'massive difference' ${ }^{30}$ between the artwork and an image of it, and Jake likewise noted that it was 'almost a privilege to go see, you know, an artist's work in person', ${ }^{31}$ neither could account for this variation. Indeed, Henry later added, 'it's still the same picture', ${ }^{32}$ while Jake concluded 'looking at say Robert Mapplethorpe's work online or in person [...] my opinions don't change really'. ${ }^{33}$ Perhaps these students are struggling with what they have been conditioned to believe, not least through the logic of undertaking college excursions - that a 'direct' encounter with an 'original' is of paramount value.

Similarly, very few students highlighted an encounter with a specific artwork from 'The Magic in the Muse' exhibition in their timelines, and when they did so this tended to be based upon a recognition of content - both Rose and Daisy mentioned by name celebrities whose portraits they had seen. In other words, while the majority of students had grasped a sense of the value attached to the opportunity afforded them, very few were able to articulate an accompanying logic, or explain how it might function in practice.

\section{Exhibition-as-interface}

In contrast, the students spoke at some length about what we would term the exhibition-asinterface, making specific reference to the way artworks were displayed and the impact and consequent meaning and value suggested. 'The Magic in the Muse' exhibition was displayed in a square, white-walled room reached by electronic glass doors. Artworks were placed at 
eye-height and a circular route was suggested by the positioning of an entry panel opposite the doors, prompting visitors to move to either side (See Figure 1).

Upon reaching the gallery the students quickly and without instruction arranged themselves into small groups and began inspecting the works in turn, the majority moving clockwise around the room. This was unexpected - the trip was supposed to begin with a staff-led tour - but the students' actions were interpreted positively by museum staff and college tutors alike, who adjusted their plans to allow for a period of self-directed engagement. During this time (the longest group taking fourteen minutes to complete a full circuit, the fastest five) the students demonstrated a number of 'ideal' gallery behaviours including talking quietly, taking photos (with permission) and making notes. The impression given to us, as observers, was of a group of young people confident with the conventional, contemplative actions routinely practiced in art museums and galleries.

The subsequent tour was explicitly based upon the three 'key themes' used to design the exhibition, so it is perhaps no surprise that students were keenly aware of the purposeful arrangement and sequencing of works. However, in the later workshops students made sophisticated comments about space and value that had little to do with these themes. Patti noted that the artworks had an increased 'impact' in the museum, attributing this to the lack of visual distraction: 'there's nothing else to focus on or like click on' ${ }^{34}$ Rose drew attention to the spacing of artworks, noting that 'in a big place like that [the museum] you can look at it [the artwork] from a distance and then go like really close up, like nose to the frame, and have a proper good look'.$^{35}$ Rose compared this with the corridor used as a display space in college, noting that the trip 'informed us [...] we're informed, but not like [pause] to that level [...] we're in a corridor and not in a museum'. ${ }^{36}$ The physical space of the exhibition afforded and encouraged a certain kind of movement and engagement not available to the students in college (on account of the crowded, narrow corridor), but it also plays into a hierarchy of knowledge and value which positions the exhibition as 'special'.

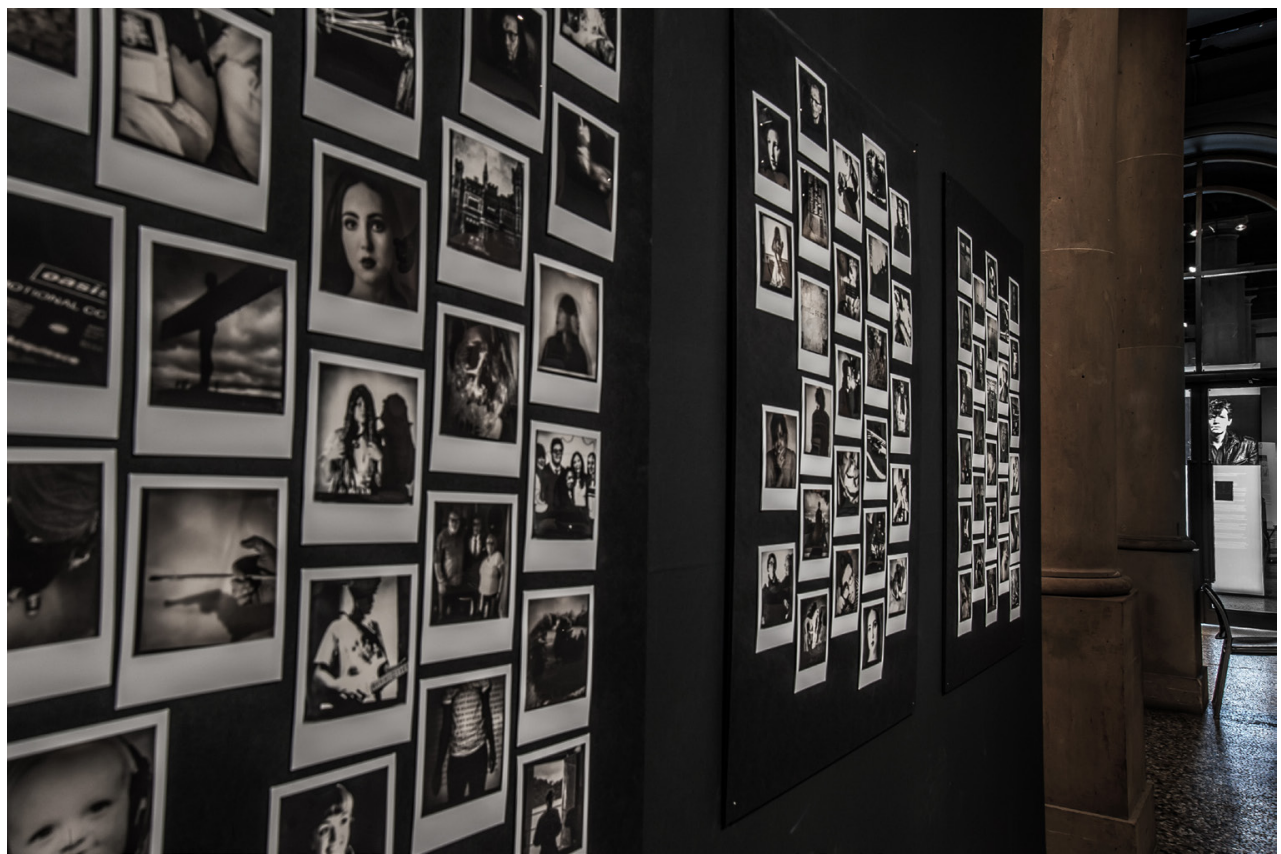

Figure 4. Image of the 'Impossible Project' display. Reproduced with permission from The Bowes Museum, Barnard Castle, County Durham, England 
The exhibition-as-interface overlaps with, and reinforces, the logic and value also suggested by the interfaces of the college, museum and artwork. But the students' recognition of this 'specialness' had at least one unintended result: they considered the positioning of the 'Impossible Project' polaroids (which they had been invited to send in) outside the main exhibition space to be indicative of the works' lesser value. Jane pointed out that the display 'felt a bit segregated', ${ }^{37}$ while Henry remarked that, 'a few people maybe thought that [the Impossible Project] was going to be a bigger thing than it was'. ${ }^{38}$ This would be disheartening news for Museum staff, whose aim had been quite the opposite. During the trip, students were observed proudly having their photos taken next to the photographs they had submitted and discussing it excitedly with peers. Yet their very ability to employ the critical 'gaze' encouraged of them elsewhere resulted in disappointment at the display techniques and spaces provided by the Museum for their own work.

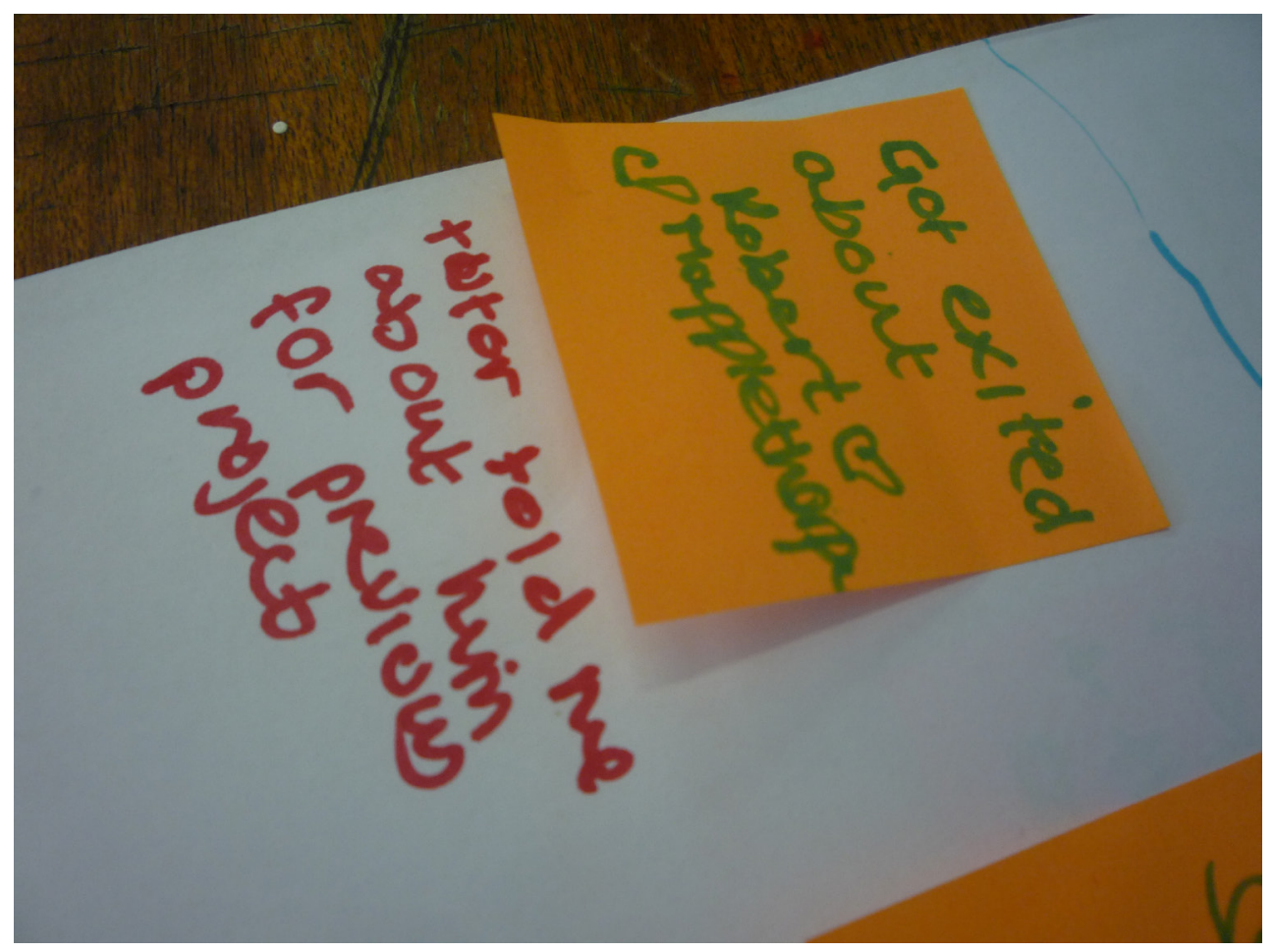

Figure 5. Image of workshop material produced by Patti.

\section{Mapplethorpe-as-interface}

Another unanticipated result of the research project was the way in which students appeared to conjure up the figure of Robert Mapplethorpe, and then 'encounter' and interact with this persona. That is, some students didn't appear to go 'through' the artwork, exhibition, Museum or college to 'get at' information about Mapplethorpe, but positioned Mapplethorpe himself as a distinct interface, albeit one whose encounter relied upon a kind of psychic or imagined connection.

The figure of Mapplethorpe brought into being by the students was clearly based upon information provided by the college, Museum, internet, exhibition and artworks (as well as additional possible sources), for Mapplethorpe died in 1989-long before the students we spoke to were born. Yet at least two students talked of Mapplethorpe in a manner that detached or 
decoupled this data from its original location. For example, Patti described Mapplethorpe as someone that 'just done what he wanted' and 'pushed it [his work] into people so that they'd get used to it', ${ }^{39}$ while Jack spoke in some detail of the way that Mapplethorpe 'went against fashions', 'was a bit [...] risqué' and sought to 'change people's views on [...] gay people'.40 The transgressive figure of Mapplethorpe suggested here is familiar but it is nevertheless an idea of Mapplethorpe, a composite of data that, crucially, is no longer 'reached' for via the artwork, Museum or college but is vividly invoked as both means and object of apprehension.

The Mapplethorpe called forth was no less transformative for his being encountered imaginatively. Jack, for example, suggested that through Mapplethorpe 'young people in general [can] realize that if they're different [...] nothing's different, like, it's good'. ${ }^{11}$ Patti made clear her personal attachment to Mapplethorpe throughout the interview. It was above all her idea or projection of him that directed her engagement with his artworks and the value she attached to them. Of course, her idea of Mapplethorpe must have been based in some part on a sense - however vague - of the imagery he produced, but nevertheless his persona took precedence in terms of value. She seemed to look closer at the works in order to make them demonstrate what she knew of him. In light of this knowledge she understood images as transgressive and bold that might, in another context, be seen as rather formal. This is all the more striking because, although there was an image of Mapplethorpe and a timeline of his career in the introductory panel, the exhibition itself concentrated on the artworks rather than Mapplethorpe the person. Patti's act of 'calling up' an idea of Mapplethorpe, inflected with specific values, transformed her way of viewing. It is partly in order to account for experiences such as these - experiences articulated with clarity and meaningfulness - that we advance a more inclusive concept of 'interfaces', so as to include within our discussion the role of nonphysical, even psychic, spaces of encounter.

\section{The self-as-interface}

The final interface to discuss here involves a similarly pyschic or 'imagined' connection, for at times the students appeared to turn to an already-formed self-schema and to 'use' the affordances of this persona as a means to navigate the activities, opportunities and transformations offered to them via other interfaces.

For example, Rose noted that she enjoyed the college project (based around album covers) because music was already important to her, ${ }^{42}$ Louise failed to be engaged by the exhibition on account of her 'not really [being] into that type of photography', ${ }^{43}$ while Jack chose not to look up the more explicit Mapplethorpe imagery, reasoning that she was, 'quite a closed person [...] l'm not comfortable with that [...] I'm an awkward person'. ${ }^{4}$ However, Jack did consider 'museum-going' to be an important part of her identity, remarking that the museum, which she visited frequently, was 'a part of me now'. ${ }^{45}$ In each case, something more than the simple expression of a personal preference appears to be taking place. In these instances, students didn't reply to our questions by saying 'I didn't like that' but rather: 'I didn't like that because I am not that kind of person'. A perceived self is at work here, and its affordances can write off, shut out, or welcome 'new' experiences. Indeed, affordances of the perceived self, in this sense, are likely to have a powerful impact upon the structuring of identities and their associated behaviours and beliefs, returning us to our earlier discussion of confusion between 'user', 'interface' and 'content'.

This leads us to a crucial point, for while the students we spoke to commonly wove their engagement with various interfaces - including the college, internet, Museum, exhibition, and artworks - into personal narratives and understandings, they never once indicated that they had changed their minds. On the contrary, students' engagements with artworks closely followed their articulated, and pre-formed, sense of self. This doesn't mean that 'transformation' in the museum or gallery isn't possible, for recognition of such moments may only come with retrospect, have been left unsaid during the workshops, been absorbed so completely as to be forgotten, or be attributable to the small sample size. This is also dependent on what we, as academics and practitioners, understand by the term 'transformation'. Nor does it mean that the trip had no impact; both Rose and Henry described the visit as 'inspirational', ${ }^{46}$ with Rose detailing the changes she had since made to her darkroom practice. ${ }^{47}$ Multiple students 
likewise commented upon the personal impression made, the new things seen and considered, or simply spoke of their enjoyment of the time away. It is, however, to sound a note of caution, and to write in favour of a more complex and detailed understanding of the nature of young peoples' engagements with and through artworks.

\section{Conclusion}

This paper has developed a humanities concept of the interface in the hope of contributing to an expanded scholarship of 'gallery learning'. This is a way of thinking about the different sites, modalities and vehicles of apprehension that constellate around students' organized encounters with art, as well as their failures, contingencies and the links and gaps between them. We have shown the complex and powerful ways that young peoples' engagements and encounters with art might be structured and directed by various interfaces, sometimes singly, but more often relationally, and how those same encounters might be extended, frustrated, missed or made meaningful in ways productive of diverse knowledges and outcomes. This complicates a monological, simplistic view of the spaces, episodes, timings, affects and effects of gallery learning and opens more expansive and nuanced understandings that might inform changes in pedagogical practice, for instance in and between schools and museums, or at the level of policy. Another critical issue is the interaction and occasional blurring between those interfaces that are imposed or prescribed, and those which students use electively.

To take an example of how this might reposition theory and practice in longitudinal understandings of learning, the constructivist figure of the 'scaffold', which suggests an upward dynamic of learning based on successive 'scaffolded' prior understandings, does not speak to the mediated production of knowledge as helpfully as our own conception of gallery learning as a set of engagements with and through serial, intersecting and sometimes clashing interfaces - a passage-through, as it were. This aligns to a degree with the longitudinal and interlocking nature of the contextual model of learning (Falk and Dierking 1992, 2013). But here too we suggest that the model's 'contexts' (personal, physical and social) are relatively blunt and undiscriminating when we seek to understand the real complexity of gallery learning. Consider, as a case in point, the productive and destructive intersections between interfaces such as college, museum, the internet, the self and the invoked figure of the artist in students' negotiated engagements with Mapplethorpe's sexual imagery, which was proscribed by the college's internet controls and not included in the exhibition. How do such intersections inflect trajectories of learning, and what indeed do students learn about in this case? They may learn not just about Mapplethorpe's work, but about their own 'natures', about the politics of access to imagery, about what can be done (and seen), when, where, how and why. This, and a range of other possibilities, suggests the need for a more nuanced, relational understanding of learning and the complexity of its production across sites.

The different types of interfaces that we have presented, including physical and nonphysical sites that have not conventionally been thought of as interfaces (e.g. a college, a sense of self), are each set within, and convey particular, political, epistemological and affective imperatives. They afford certain modes of engagement and not others, producing certain kinds of learning experience and not others. They cannot usually be considered discretely because it is more normal that they are encountered in more or less tense combination and interaction. Critically, this is unlikely to produce identical effects over different situations and subjects, but rather a multitude of trajectories of learning that are surely hard to predict or control. This complicates any attempt to encode ideal transformations into the experience of the gallery visit.

Many more interfaces might yet be explored. More research needs to explore the ways in which different interfaces reinforce, inflect, conflict and combine to make learning possible (or not) for individual subjects. Our data represent only a small proportion of a handful of students' lives. Yet this work, carried out in depth and over time, necessitates a shift in focus. We need to move beyond the episode of the gallery visit, and to understand (often complex) encounters with artworks within the far broader range of modalities and within the richer context of a life lived. 


\section{Acknowledgements}

We would like to sincerely thank the students who participated in this research project, their college tutors, and staff at the Bowes Museum for so generously sharing their thoughts and time with us. We also thank the anonymous reviewers who provided helpful comments on our submission. This research was funded by the School of Arts and Cultures, Newcastle University.

\section{Notes}

1 DCMS (2016) The Culture White Paper https://www.gov.uk/government/uploads/system/ uploads/attachment data/file/510798/DCMS The Culture White Paper 3 .pdf accessed 9 January 2017.

2 For additional research concerning the AR touring programme, and particularly the 'Artcasting' project exploring digital arts-based engagement and evaluation, see Ross et al (2017) and Ross (2017).

3 Museum Staff One, interview with authors, digital recording, 24th February 2016, County Durham

4 The Bowes Museum (2017) 'Visitor Information' http://thebowesmuseum.org.uk/Visit-Us/ Visitor-Information accessed 9 January 2017

5 Given the age of the students, the research process was conducted with an ethics of respect for all those involved, in compliance with BERA's Ethical Guidelines for Educational Research (2011) and with full ethical clearance obtained from Newcastle University. See British Educational Research Association [BERA] (2011) Ethical Guidelines for Educational Research [online] Available at https://www.bera.ac.uk/wp-content/uploads/2014/02/BERAEthical-Guidelines-2011.pdf?noredirect=1 accessed 25 July 2017

6 Henry, workshop with authors, digital recording, 24th March 2016, North-East England

7 Henry, workshop, 24th March 2016

8 Tutor One, interview with authors, digital recording, 7th October 2015, North-East England

9 Louise, workshop with authors, digital recording, 24th March 2016, North-East England

10 Daisy, workshop with authors, digital recording, 24th March 2016, North-East England

11 Patti, workshop with authors, digital recording, 24th March 2016, North-East England

12 Jake, workshop with authors, digital recording, 24th March 2016, North-East England. By 'classical', Jake was not referring to Graeco-Roman art, but rather art that pre-dated his sense of 'modern'.

13 Patti, workshop, 24th March 2016

14 Jack, workshop with authors, digital recording, 24th March 2016, North-East England

15 Jack, workshop, 24th March 2016

16 Rose, workshop with authors, digital recording, 24th March 2016, North-East England

17 Jane, workshop with authors, digital recording, 24th March 2016, North-East England

18 Henry, workshop, 24th March 2016

19 Jane, workshop, 24th March 2016 
20 Rose, workshop, 24th March 2016

21 Museum Staff Two, interview with authors, digital recording, 24th February 2016, County Durham

22 Jack, workshop, 24th March 2016

23 Daisy, workshop, 24th March 2016

24 Patti, workshop, 24th March 2016

25 Patti, workshop, 24th March 2016

26 Nicola, workshop with authors, digital recording, 24th March 2016, North-East England

27 Nicola, workshop, 24th March 2016

28 Rose, workshop, 24th March 2016

29 Jane, workshop, 24th March 2016

30 Henry, workshop, 24th March 2016

31 Jake, workshop, 24th March 2016

32 Henry, workshop, 24th March 2016

33 Jake, workshop, 24th March 2016

34 Patti, workshop, 24th March 2016

35 Rose, workshop, 24th March 2016

36 Rose, workshop, 24th March 2016

37 Jane, workshop, 24th March 2016

38 Henry, workshop, 24th March 2016

39 Patti, workshop, 24th March 2016

40 Jack, workshop, 24th March 2016

41 Jack, workshop, 24th March 2016

42 Rose, workshop, 24th March 2016

43 Louise, workshop, 24th March 2016

44 Jack, workshop, 24th March 2016

45 Jack, workshop, 24th March 2016

46 Henry and Rose, separate workshops, 24th March 2016

47 Rose, workshop, 24th March 2016 


\section{References}

ARTIST ROOMS 'Learning' http://www.tate.org.uk/artist-rooms/learning accessed 09/01/2017

Ash, J. (2015) The Interface Envelope: Gaming, Technology, Power. London: Bloomsbury Publishing Inc.

Barrett, J. and Millner, J. (2014) Australian Artists in the Contemporary Museum, Surrey: Ashgate

Beckmann, E. A. (2013) 'Internships in Museum Studies: Learning at the Interface', in Boddington, A., Boys, J., and Speight, C., (eds) Museums and Higher Education Working Together: Challenges and Opportunities, Surrey: Ashgate Publishing Ltd

Brown, C., Wood, E. and Salgado, G. (2016) (eds) Inspiring Action: Museums and Social Change, Boston MA: MuseumsEtc

Bourdieu, P. and Darbel, A. (1969) The Love of Art, Les Editions de Minuit, Paris

Drucker, J. (2011) 'Humanities Approaches to Interface Theory', Culture Machine 12 (1) $1-20$

Falk, J. H. and Dierking, L. D. (1992) The Museum Experience, Washington, DC: Whalesback Books

(2013) The Museum Experience Revisited, Walnut Creek, CA: Left Coast Press Inc.

Gibson, J.J. (1977) 'The Theory of Affordances' in R. Shaw and J. Bransford (eds.). Perceiving, Acting, and Knowing: Toward an Ecological Psychology, 119-48, Hillsdale, NJ: Lawrence Erlbaum.

Greeno, J.G. and the Middle-School Mathematics through Application Project Group, (1998), 'The situativity of knowing, learning, and research' American Psychologist, $53,5-26$

Griffin, J. (2004) 'Research on Students and Museums: Looking More Closely at the Students in School Groups', Science Education, 88 (1) 59-70

Hein, G. E. (1998) Learning in the Museum, London: Routledge

Hooper-Greenhill, E. [ed] (1999) The Educational Role of the Museum [2 ${ }^{\text {nd }}$ edition]. Abingdon: Oxon: Routledge.

(2004) 'Measuring learning Outcomes in Museums, Archives and Libraries: The Learning Impact Research Project (LIRP)', International Journal of Heritage Studies 10 (2) $151-174$

Johnston-Feller, R. (2001) Colour Science in the Examination of Museum Objects: Nondestructive Procedures, Los Angeles: The Getty Conservation Institute

Kidd, J. 2011. 'Enacting Engagement Online: Framing social media use for the museum' Information, Technology and People, 24 (1) 64-77

Kidd, J., and Cardiff, R. (2017) “A Space of Negotiation': Visitor Generated Content and Ethics at Tate', Museum and Society, 15 (1) 43-55 
Laurel, B. (1990) The Art of Human-Computer Interface Design, Reading, MA: AddisonWesley

Marty, P. F. (2007) 'Museum Websites and Museum Visitors: Before and After the Museum Visit', Museum Management and Curatorship, 22 (4) 337-360

Mason, R. (2005) 'Museums, Galleries and Heritage: Sites of Meaning-Making and Communication', in Corsane, G. (ed.) Heritage, Museums and Galleries: an introductory reader, London and New York: Routledge

Mayrand, Y. (2001) 'The Role of the Exhibition Designer', in Lord, B., and Dexter Lord, G. (eds) The Manual of Museum Exhibitions Oxford: AltaMira Press

Molinaro, M., McLuhan, C. and Toye, W. (eds) (1987) Letters of Marshall McLuhan Oxford: Oxford University Press

Newman, A., and McLean, F. (2004) 'Presumption, Policy and Practice' International Journal of Cultural Policy, 10 (2) 167-181

Pringle, E. and DeWitt, J. (2014) 'Perceptions, Processes and Practices Around Learning in an Art Gallery', Tate Papers (22) http://www.tate.org.uk/research/publications/tatepapers/22/perceptions-processes-and-practices-around-learning-in-an-art-gallery

Ross, J., Sowton, C., Knox, J. and Speed, C. (2017). 'Artcasting, mobilities, and inventiveness: engaging with new approaches to arts evaluation' in L. Ciolfi, A. Damala, E. Hornecker, M. Lechner, L. Maye (eds) Cultural Heritage Communities: Technologies and Challenges, 150-165, Oxford and New York: Routledge

Ross, J. (2017). 'If it's creative, it doesn't feel like evaluation: implications for practice from the Artcasting project'. The Museum Review, 2 (1) 1-11

Sandell, R. (1998) 'Museums as Agents of Social Inclusion', Museum Management and Curatorship, 14 (4) 401-418

Simon, N. (2010) The Participatory Museum. Santa Cruz, California: Museum 2.0 http:// www.participatorymuseum.org

Soren, B. J. (2009) 'Museum experiences that change visitors', Museum Management and Curatorship, 24 (3) 233-251

Suchy, S. (2004) Leading with Passion: Change Management in the $21^{\text {st }}$-Century Museum, Walnut Creek, CA: AltaMira Press

Whitehead, C. (2012) Interpreting Art in Museums and Galleries, London and New York: Routledge

Yu-Chang Li, R. and Wee-Chung Liew, A. (2015) 'An Interactive User Interface Prototype Design for Enhancing On-site Museum and Art Gallery Experience Through Digital Technology', Museum Management and Curatorship 30 (30) 208-229

Xanthoudaki, M. (2015) 'Museums, Innovative Pedagogies and the Twenty-First Century Learner: A Question of Methodology', Museum \& Society 13 (2) 247-265 


\begin{abstract}
Authors
*Lead author Prof Christopher Whitehead

Christopher Whitehead is Professor of Museology at Newcastle University and Professor II at the University of Oslo. He trained and worked as an art historian and art curator, but his research activities today are much broader. They encompass the cultural politics of heritage and memory, display, knowledge construction, interpretation and the relations between place, time and identity. His books include The National Art Museum in $19^{\text {th }}$-Century Art Britain (2005), Museums and the Construction of Disciplines (2009), Interpreting Art in Museums and Galleries (2012), Placing Migration in European Museums (2012) and Museums, Migration and Identity in Europe (2015).
\end{abstract}

\title{
${ }^{* *}$ Co-author Dr Emma Coffield
}

Dr Emma Coffield is an Early Career Academic Fellow in Media, Culture, Heritage (MCH) at Newcastle University, where she co-leads the Art Museum and Gallery Studies MA programme. Her research interests tend to be interdisciplinary and draw upon museum studies, cultural sociology, and art history. Her work to date has focused upon the everyday experiences of contemporary art practitioners and audiences, the nature of belonging and artistic identity, and the spatial politics of art.

\section{Address:}

Media, Culture, Heritage

School of Arts and Cultures

Armstrong Building

Newcastle University

Newcastle upon Tyne

NE1 7RU

Email:

chris.whitehead@newcastle.ac.uk

emma.coffield@newcastle.ac.uk 